\title{
Determinants of Internet Usage During COVID-19 on the Young People in Dhaka, Bangladesh
}

\author{
Apu Chandra Das ${ }^{1}$, Aninda Roy ${ }^{2}$, Md Sakib Ibne Salam², \\ ${ }^{1}$ University of Arkansas, Fayetteville, Arkansas, USA \\ ${ }^{2}$ Minnesota State University, Mankato, Minnesota, USA \\ ${ }^{3}$ University of Dhaka, Dhaka, Bangladesh \\ * Corresponding author email: acdas@uark.edu
}

Received: 20 June 2020 / Revised: 23 September 2020 / Accepted: 03 October 2020 / Published: 04 October 2020

\begin{abstract}
As the COVID-19 pandemic is spreading and becoming more contagious, people tend to stay home and face mental health challenges such as anxiety, fear, nervousness, and loneliness. In this time, students are using the internet heavily for their study purpose, and jobholders are for their official works. At the same time, the use of the internet might be a relief from those mental challenges. This manuscript assesses a correlation between daily internet usage before and during COVID-19 and found to be nearly strong positive $(\mathrm{r}=0.66)$. Then we determine the potential factors affecting daily internet usage during COVID-19 among Bangladeshi students and jobholders who are currently living in Dhaka city by the ordinary least square (OLS) regression method. Our results underpin that the type of internet, regular internet usage before COVID-19, and the effect of internet usage on the study are significantly affecting current internet usage.
\end{abstract}

Keywords: COVID-19, Bangladesh, Daily internet usage, Type of internet, Mental health challenge.

\section{Introduction}

In December 2019, a pneumonia-like infectious disease was diagnosed in Wuhan, Hubei province of China, and was later determined to be caused by a novel coronavirus (2019-nCoV). The outbreak has spread mainland in China and eventually globally. With this novel coronavirus outbreak, the World Health Organization (WHO) announced the disease as a pandemic and an international public health emergency. As of September 22, coronavirus disease 2019 (COVID-19) has been confirmed in 31,675,961 people worldwide, carrying 972,625 confirmed deaths. The patients who have been infected show serious respiratory problems and cardiovascular diseases (Zheng et al., 2020). Besides, it causes mental health problems. A study (Huang et al., 2020) was conducted on the medical staff in China, and $23 \%$ of them found mentally anxious and nervous. These mental issues might lead people to commit suicidal activities. $90 \%$ of the suicidal activities worldwide happen due to depression-like mental health conditions (Mamun and Griffiths, 2020b). In this current outbreak, a Bangladeshi guy committed suicide from a building's rooftop because of mental anxiety and fear (Mamun and Griffiths, 2020a). A study showed that the suicide rate increased during the SARS outbreak in Hong Kong among older people (Cheung et al., 2008).

As there are no vaccines or curable drugs found yet, the WHO recommends following some preventive measures such as social-distancing, isolation, and quarantine to flatten the exponential infection growth. Some countries announce lockdown nationwide to reduce the transmission of this infectious disease. During the lockdown, people are not allowed to step out except for emergency cases. They are bored with staying home for a long time, resulting in mental health crises such as depression, loneliness, fear, nervousness, and anger. In that case, internet usage might play an important role. People can get online mental health interventions browsing through cost-effective and convenient (Barak and Grohol, 2011). These interventions include psychoeducational static webpages, video conferencing, and professional-led online therapy (Barak and Grohol, 2011). 
Young people are experiencing more mental health crises than their adult counterparts as they are losing their jobs and cannot continue their studies. Even they face difficulties in accessing mental health services because of the superstition related to mental health problems. Internet-based health services might be useful in reducing mental health problems (Griffiths and Christensen, 2007). A study (Horgan and Sweeney, 2010) was conducted on 922 university students using the internet for mental health support and information. The results showed that $72.4 \%$ of respondents used the internet multiple times a day, and the other $30.8 \%$ had previously used for mental health information and solution online, especially on depression. However, $79.4 \%$ would still prefer face-to-face assistance if they need to. Therefore, the government should improve the online health service system and employ some skilled psychiatrists and physicians. Online medical services might play an important role in rural regions as there is a shortage of accessibility of face-to-face services (Griffiths and Christensen, 2007). Even during the outbreak, it is far better to stay home and receive online-based health services, which would reduce the chance of being infected.

In Bangladesh, the government shut down the educational institutions on March 26 (Anwar et al., 2020), and students were immediately sent back home from their dormitories. A significant percentage of university students are from rural regions, and their only income source is private tutoring (PT). They are going through a tough time as they lost their PT opportunities. The internet might play a vital role in that case, and they can continue their PT service online, even earn extra money through freelancing. Universities have stopped all regular activities, including classes and exams, which must create a session jam. They can resume their services online using a virtual platform such as Skype, Zoom, Microsoft Team, though overuse might affect their academic performance (Frangos, 2009). Our result shows that $58.8 \%$ of participants think internet usage affects their study.

Because of the viral outbreak, most government and non-government companies pause their activities, which would impact their revenue and the employees as well. They can resume their services online and allow their employees to work from home. Though some companies have already started that, their efficiency is not the same as before (Joob and Wiwanitkit, 2020). Our result shows that $63.2 \%$ of people think social distancing affects their study and job efficiency.

\section{Materials and Method}

We collected data through the google docs platform from the population who used to live in the city of Dhaka, Bangladesh. The whole study population has been divided into three sub-categories based on their age, such as below 16,16-61, and above 61. As the people of two extreme categories barely use internet and our primary focus is on internet usage, we choose the young people (16-61) as our study population. We shared our survey link through social media as well as reached out to some known participants to participate in the survey. The survey includes detail information about a participant's location within Dhaka city, his/her age, gender, marital status, occupation, the highest degree of education, monthly income, internet usage (before \& during) medium of receiving updates on COVID-19, feeling about social distancing, the effect of social distance on study or job efficiency, quarrelsome behavior in the residence, mental health challenges, availability of enough space in residence for self-isolation, hygiene situation, daily hand washing, leaving home during the last 14 days, experiencing any physical problem, financial assistance, and medium of collecting food. Our dependent variable is continuous; how many hours in a day respondent use the internet during the COVID-19 pandemic. Independent variables are a combination of both continuous and categorical.

Our survey respondents are mainly college/ university students (59.4\%) and jobholders (25.1\%) and aged between 16-61 with the mean age of 25.13. We collected a sample of 250 from the entire city, irrespective of region, gender, race, and ethnicity. Our sample contains 36.3\% female and $63.3 \%$ male; among them, $42.6 \%$ of the total respondents live in the off-campus but the same city or town $(42.6 \%)$. Due to all educational institutions' sudden shutdown, only $6.4 \%$ of the respondents stayed on-campus housing. We also found that $36.3 \%$ of respondents use mobile data, $30.6 \%$ use the broadband internet connection, and $33.1 \%$ use both. As the high-speed cable internet connection is not available in rural areas, people tend to 
Apu Chandra Das et al., Adv. J Social Sci.; Vol. 7, Issue 1, pp: 118-124, 2020

be using more mobile data. Before the pandemic, mean internet usage was 4.21 hours per day, which increases more than 70\% during this pandemic (Mean Internet usage during a pandemic is 7.42 hours per day). Because the internet is the only way of recreation in this pandemic, all educational institutions start online classes. Many jobholders have to maintain their office time from home (work from home). From all the respondents, $19.5 \%$ strongly agree, and 39\% agree that internet usage affects their study and daily work life. $26.3 \%$ of respondents disagree, and $13.5 \%$ strongly disagree that "Work from Home" and "Online Class" is adequate during this pandemic.

At first, we find a relationship between daily internet usage before and during COVID-19 by using Pearson's correlation. We then fit an Ordinary Least Square (OLS) regression model to estimate daily internet usage based on the respondents' information. Our dependent variable is continuous; how many hours a day respondent uses the internet during the COVID-19 pandemic. Independent variables are a combination of both continuous and categorical.

\section{Results and Discussion}

\subsection{Correlation Between Daily Internet Usage Before and During COVID-19}

Pearson's correlation coefficient is a measure of statistical relationship, or association when two variables are continuous. It provides information about the magnitude of the association and the direction of the relationship. In that case, the amount of daily internet usage before and during COVID-19 are continuous variables. Pearson's correlation can be defined as

$$
r=r_{x y}=\frac{\operatorname{cov}(x, y)}{S_{x} \cdot S_{y}}
$$

where x and y are two continuous variables, and $S_{x}$ and $S_{y}$ are their corresponding standard deviations.

Figure 1 shows a scatter plot between daily internet usage before and during COVID-19. The majority of people use 2-15 hours of internet daily with a mean of 7.4. The correlation coefficient found to be $r=0.66$ which shows a moderately positive linear relationship between the internet usage before and after COVID19. Furthermore, the smoothing line shows a positive relationship between them.

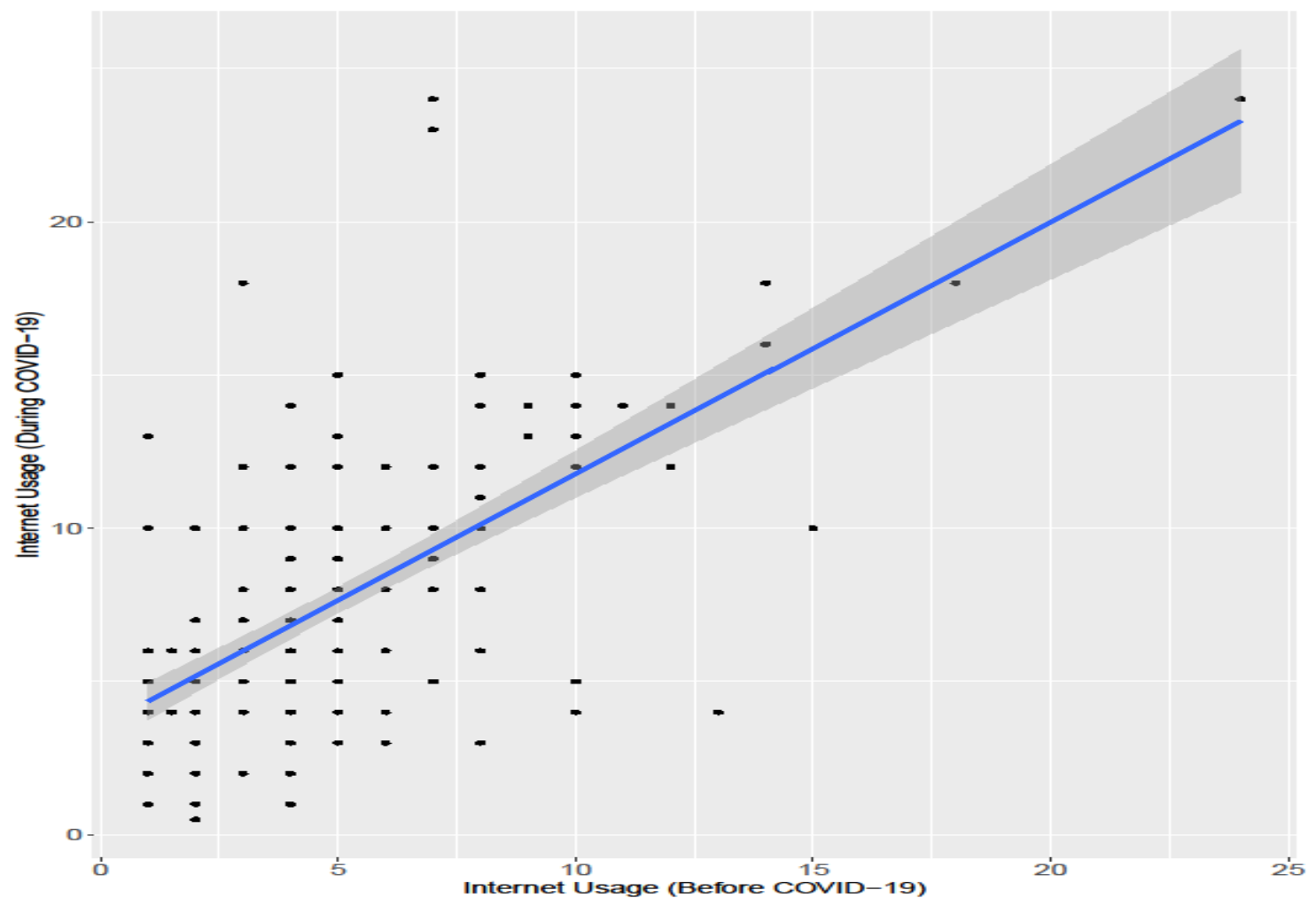

Figure 1: Scatter plot 


\subsection{Factors Influencing Daily Internet Usage During COVID-19}

What factors determine the daily internet usage during COVID-19? There might be many factors such as age, gender, region, occupation, monthly income, type of internet, etc. We aim to find a set of significant covariates using the ordinary least square (OLS) regression model as our response variable is continuous, as well as $n>p$. For this regression model, we use a sample of size 250 and a set of 7 covariates. Continuous predictors are directly used in the model, while we create dummy variables for categorical predictors and consider the first category of each variable as a reference or baseline category. We estimate the following model:

DailyInternetUsageDuringCOVID19 $=b_{0}+b_{1}$ Age $+b_{2}$ Gender(Female $)+b_{3}$ Gender(Other) + $b_{4}$ MaritalStatus(Unmarried) $+b_{5}$ MaritalStatus(Divorced) $+b_{6}$ InternetType(Broadband) + $b_{7}$ InternetType(Both) $+b_{8}$ DailyInternetUsageBeforeCOVID19 $+b_{9}$ AffectStudy(Disagree) $+b_{10}$ AffectStudy(Neutral) $+b_{11}$ AffectStudy(Agree) $+b_{12}$ AffectStudy(Strongly agree) + $b_{13}$ MentalHealthChallenge(No) +Error

Table 1: OLS regression model for DailyInternetUsageDuringCOVID19

\begin{tabular}{|l|c|c|c|c|}
\hline \multicolumn{1}{|c|}{ Variable } & Estimate & Standard Error & t-value & $\operatorname{Pr}(>|\mathrm{t}|)$ \\
\hline Intercept & 3.538 & 1.774 & 1.995 & $0.047 *$ \\
\hline Age & -0.069 & 0.044 & -1.567 & 0.118 \\
\hline Gender (Female) & -0.308 & 0.429 & -0.718 & 0.473 \\
\hline Gender (Other) & -2.824 & 3.141 & -0.899 & 0.370 \\
\hline Marital Status (Unmarried) & 0.466 & 0.602 & 0.773 & 0.440 \\
\hline Marital Status (Divorced) & 2.241 & 1.905 & 1.176 & 0.241 \\
\hline Internet Type (Broadband) & 1.780 & 0.492 & 3.618 & $0.000^{* * *}$ \\
\hline Internet Type (Both) & 1.388 & 0.479 & 2.899 & $0.004 * *$ \\
\hline Daily Internet Usage Before COVID19 & 0.831 & 0.060 & 13.838 & $0.000 * * *$ \\
\hline Affect Study (Disagree) & -0.320 & 1.220 & -0.263 & 0.793 \\
\hline Affect Study (Neutral) & 0.297 & 1.114 & 0.267 & 0.790 \\
\hline Affect Study (Agree) & 0.514 & 1.078 & 0.477 & 0.634 \\
\hline Affect Study (Strongly agree) & 1.923 & 1.125 & 1.709 & 0.089. \\
\hline Mental Health Challenge (No) & -0.558 & 0.416 & -1.341 & 0.181 \\
\hline
\end{tabular}

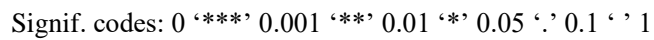

F-statistic: 19.39, p-value: 0.000, Multiple R-squared: 0.517, Adjusted R-squared: 0.49

Table 1 shows the summary statistics of the above-fitted model. We report estimated coefficients, their standard errors, $\mathrm{t}$-values, and p-values correspondingly. We found Intercept, InternetType(Broadband), InternetType(Both), DailyInternetUsageBeforeCOVID19, AffectStudy(Strongly agree) significant to estimate the daily internet usage during COVID-19 and rest of them are insignificant. If there are no covariates in the model, then, on average, people use an estimate of 3.54 hours of internet daily during the current outbreak than before. Fixing all other predictors, if we change the type of internet from mobile data to broadband, then the estimated mean of the daily internet usage (during) will increase by 1.78 hours. That means the individual who has broadband internet connection uses, on average, 1.78 hours more internet daily than who uses mobile data. Similarly, who has both mobile data and broadband connection uses, on average, 1.38 times more internet daily than who has an only mobile data connection. Another significant covariate is daily internet usage before COVID-19, with an estimated coefficient of 0.831 . Fixing all other covariates, if an individual uses the internet one more hour daily before COVID-19, then the estimated mean of his/her internet usage will increase by 0.83 hours during the COVID-19 pandemic. At last, the participants who strongly agree that internet usage affects their study use 1.92 hours more internet daily than those who think internet usage does not affect their study at all. 
Apu Chandra Das et al., Adv. J Social Sci.; Vol. 7, Issue 1, pp: 118-124, 2020

Also, from the F-statistic and corresponding p-value, it can be said that some of the coefficients are zero and do not have any significant impact on the regression model. Adjusted R-square $=0.49$ tells the predictors explain $49 \%$ of the response variable.

A Normal QQ plot is a probability plot, which shows a comparison between two probability distributions by plotting their quantiles. If the two distributions are similar, then the points will lie on the straight line approximately. This plot can be used to test the goodness of fit of a fitted regression model. The residuals of a fitted regression model are normally distributed if they lie on
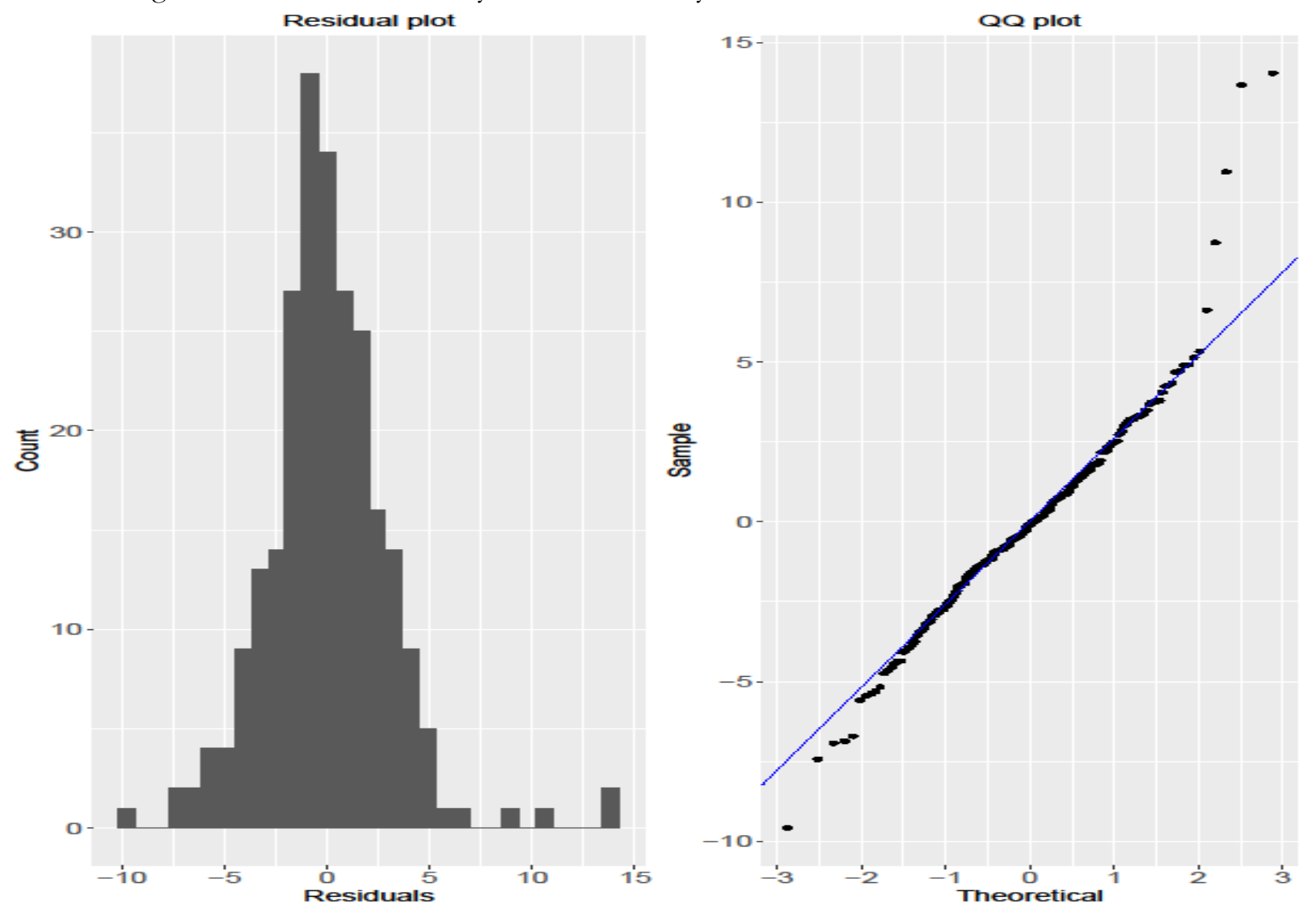

Figure 2: Residual plot and $Q Q$ plot

a straight line, which is a desirable property of a fitted model. We will be in trouble if the residuals do not follow a normal distribution. Figure 2 shows a histogram of the residuals and a Normal QQ plot. The histogram looks like an approximately normal distribution except some outliers, and the residuals on the QQ plot lie on a straight line, which underpins that residuals do follow a normal distribution, and our model fits the data well eventually.

\section{Conclusions}

In this study, we predict the daily internet usage during COVID-19 using the OLS regression model and type of internet, regular internet usage before COVID-19, and the effect of internet usage on the study found to be significant. It shows that the people who use broadband internet tend to be using more internet daily because of its affordability and high speed compared to the mobile data. Other apparent reasons for using more internet during the pandemic are that some universities offer virtual classes and employees work from home. As the outbreak is spreading and tends to be prolonged, people are facing mental health challenges like anxiety, fear, nervousness, and loneliness. During the lockdown, people use 7.42 hours of internet daily, on average, with a standard deviation of 4.28 hours. People likely to use mobile data $(36.4 \%)$ as they moved to their village, and there is no high-speed cable internet connection. The internet can be a valuable source in this pandemic situation if they use it more effectively. Unlike earlier, people should not 
run to the nursing home with minor injuries or mild symptoms like fever, cough. To overcome this situation, the government should open a virtual health care facility, such as online counselling and telemedicine service, which would relieve them from their mental challenges.

\section{Declarations}

\subsection{Study Limitations}

As the survey was conducted through social media, we were unable to reach out to the people of all age categories. We collected data mainly from the young people, ranges from 18 to 61 .

\subsection{Acknowledgements}

We would like to express our sincere gratitude to all our teachers for their consistent assistance during this manuscript preparation and beyond. Their patience, encouragement, knowledge, and guidance helped us in all the time of research and writing of this work. We would also like to thank all the participants who directly took part in our study by providing valuable information. This work was carried out in collaboration and hard work of all authors. Finally, we must express our very cordial gratitude to our beloved parents and family for providing us with unfailing support and continuous encouragement throughout our years of study and through the process of researching and writing this manuscript.

\subsection{Survey Duration}

This survey has been taken place from May 12, 2020 through May 17, 2020 when the COVID-19 confirmed cases was increasing significantly.

\subsection{Informed Consent}

Consent was sought at the beginning of the survey from the participants. We included only the individuals who had wanted to take part in the survey.

\subsection{Competing Interests}

We declare that there is no competing interest regarding this survey.

\section{How to Cite this Article}

Das, A. C., Roy, A., \& Salam, M. S. I. (2020). Determinants of Internet Usage During COVID-19 on the Young People in Dhaka, Bangladesh. Advanced Journal of Social Science, 7 (1), 118-124. https://doi.org/10.21467/ajss.7.1.118-124

\section{References}

[1] Anwar, S., Nasrullah, M., and Hosen, M. (2020). Covid-19 and Bangladesh: Challenges and how to address them. front. Public Health, 8:154.

[2] Barak, A. and Grohol, J. M. (2011). Current and future trends in internet-supported mental health interventions. Journal of Technology in Human Services, 29(3):155-196.

[3] Cheung, Y., Chau, P. H., and Yip, P. S. (2008). A revisit on older adults suicides and severe acute respiratory syndrome (sars) epidemic in Hong Kong. International Journal of Geriatric Psychiatry: A journal of the psychiatry of late life and allied sciences, 23(12):12311238.

[4] Frangos, C. C. (2009). P01-31 internet dependence in college students from Greece. European Psychiatry, $24:$ S419.

[5] Griffiths, K. M. and Christensen, H. (2007). Internet-based mental health programs: A powerful tool in the rural medical kit. Australian Journal of Rural Health, 15(2):81-87.

[6] Horgan, A. and Sweeney, J. (2010). Young students' use of the internet for mental health information and support. Journal of psychiatric and mental health nursing, 17(2):117-123.

[7] Huang, J., Han, M., Luo, T., Ren, A., and Zhou, X. (2020). Mental health survey of 230 medical staff in a tertiary infectious disease hospital for covid-19. Zhonghua lao dong wei sheng zhi ye bing za zhi=Zhonghua laodong weisheng zhiyebing zazhi= Chinese journal of industrial hygiene and occupational diseases, 38:E001-E001.

[8] Hye, H. A. et al. (1996). Below the line: rural poverty in Bangladesh. University Press Limited.

[9] Islam, M. D. and Siddika, A. (2020). Covid-19 and Bangladesh: A study of the public perception on the measures taken by the government.

[10] Joob, B. and Wiwanitkit, V. (2020). Traumatization in medical staff helping with covid-19 control. Brain, Behavior, and Immunity.

[11] Khandker, S. R. (2012). Seasonality of income and poverty in Bangladesh. Journal of Development Economics, 97(2):244-256. 
Apu Chandra Das et al., Adv. J Social Sci.; Vol. 7, Issue 1, pp: 118-124, 2020

[12] Mamun, M. A. and Griffiths, M. D. (2020a). First covid-19 suicide case in Bangladesh due to fear of covid-19 and xenophobia: Possible suicide prevention strategies. Asian journal of psychiatry, 51:102073.

[13] Mamun, M. A. and Griffiths, M. D. (2020b). A rare case of Bangladeshi student suicide by gunshot due to unusual multiple causalities. Asian journal of psychiatry, 49:101951.

[14] Zabir, A. A., Mahmud, A., Islam, M. A., Antor, S. C., Yasmin, F., and Dasgupta, A. (2020). Covid-19 and food supply in Bangladesh: A review. Available at SSRN 3595967.

[15] Zheng, Y.-Y., Ma, Y.-T., Zhang, J.-Y., and Xie, X. (2020). Covid-19 and the cardiovascular system. Nature Reviews Cardiology, 17(5):259-260.

Publish your research article in AIJR journals-

$\checkmark$ Online Submission and Tracking

$\checkmark$ Peer-Reviewed

$\checkmark \quad$ Rapid decision

$\checkmark \quad$ Immediate Publication after acceptance

Articles freely available online

Retain full copyright of your article.

Submit your article at journals.aijr.in
Publish your books with AIJR publisher-

$\checkmark \quad$ Publish with ISBN and DOI.

$\checkmark \quad$ Publish Thesis/Dissertation as Monograph.

$\checkmark \quad$ Publish Book Monograph.

$\checkmark$ Publish Edited Volume/ Book.

$\checkmark \quad$ Publish Conference Proceedings

Retain full copyright of your books.

Submit your manuscript at books.aijr.org 